\title{
Review \\ The Development and Application of a TFM for Dense Particle Flow and Mixing in Rotating Drums
}

\author{
Wenjie Rong ${ }^{1,2, * \mathbb{C}}$, Baokuan $\mathrm{Li}^{1}$ and Yuqing Feng ${ }^{3}$ \\ 1 School of Metallurgy, Northeastern University, Shenyang 110819, China; libk@smm.neu.edu.cn \\ 2 State Key Laboratory of Process Automation in Mining \& Metallurgy, Beijing 102628, China \\ 3 CSIRO Mineral Resources, Melbourne, VIC 3168, Australia; Yuqing.Feng@csiro.au \\ * Correspondence: rongwenjie@smm.neu.edu.cn
}

check for updates

Citation: Rong, W.; Li, B.; Feng, Y. The Development and Application of a TFM for Dense Particle Flow and Mixing in Rotating Drums. Processes 2022, 10, 234. https://doi.org/ $10.3390 /$ pr10020234

Academic Editors: Haiping Zhu and Chandana Jayasundara

Received: 6 January 2022

Accepted: 23 January 2022

Published: 26 January 2022

Publisher's Note: MDPI stays neutral with regard to jurisdictional claims in published maps and institutional affiliations.

Copyright: (C) 2022 by the authors. Licensee MDPI, Basel, Switzerland. This article is an open access article distributed under the terms and conditions of the Creative Commons Attribution (CC BY) license (https:// creativecommons.org/licenses/by/ $4.0 /)$.

\begin{abstract}
The two-fluid model (TFM) coupled with the kinetic theory of granular flow (KTGF) has gradually been used for modeling dense granular flows and mixing in rotating drums in recent years. In the present paper, a review is made from the perspective of model development and model application. It is found that several frictional viscosity models were proposed to consider the enduring contact of dense particles for the specific rotating studied, but there is still a lack of a universal model. The model is validated by various experiment results and the applicability is indicated. The model is used for investigating dynamic particle flow, and the effects of the parameters on granular flow behavior and flight design. Although the model theoretically has the advantage of saving computing resources, and is suitable for industrial-scale modeling, it is found that the model is used for the research of laboratory-scale rotating drums (diameter less than $0.5 \mathrm{~m}$ ) and has not been used for industrial rotating drum analysis. Moreover, recommendations for future work are provided.
\end{abstract}

Keywords: dense granular flow; rotating drum; flow and mixing; two-fluid model; kinetic theory of granular flow

\section{Introduction}

Granular matter are ubiquitous in our daily lives and in industries, but they behave differently from other familiar forms of matter, such as solids, liquids and gases [1]. Some researchers have even suggested that granular medium be considered as an additional form of substance existence [2]. The science of granular media has a long history [3], but the description of granular flow still remains an open issue due to its intriguing range of complex, nonlinear behavior. Because of their practicability and complexity, knowledge of the dynamics of particles is of high interest in engineering and academia. Among the many varieties of particle processing equipment, the rotating drum is a typical one with dense granular flow inside, and it is widely used in the industry for mixing, drying, milling, coating, or granulation/agglomeration [4]. Particle flow in rotating drums exhibits a range of complex phenomena, such as avalanche, segregation, and convection [5]. Therefore, the current paper focus on dense granular flow in rotating drums.

The diameter of the rotating drum used in the industry ranges from a few meters to tens of meters, and the number of particles in it is huge. Therefore, the cost of industrialscale experimental research is quite high. Moreover, it is difficult to get the particle scale information accurate in experiments [6]. With the rapid development of computers, numerical methods provide an effective and cost-saving alternative way to study particle flow behavior in rotating drums. The two common numerical methods are the discrete element method (DEM) and the two-fluid model (TFM). DEM has been applied in this area since the 1990s [7]. DEM calculates the motion and force equation of individual particles, so it can provide valuable particle scale information, such as coordinate number, collision 
velocity, and collision frequency [8]. However, due to limited computing resources, DEM is not suitable to study the industrial scale rotating drum [9]. In contrast, TFM treats the gas and particles as fluids that can penetrate each other, greatly reducing the amount of calculation and becoming a preferred model for particle flow calculation in industrial-scale rotating drums [10].

Aiming to promote the development of TFM to deepen the understanding of the dynamic behavior of granular flow in rotating drums, a comprehensive review is given in this paper. In this review, TFM used for modeling dense particle flow and mixing in rotating drums is summarized and discussed from the perspective of model development and model application. It is intended to explore the applicability and limitations of the model. In the meantime, it is committed to revealing what aspects of the model have been studied on particle dynamics and how exactly the model is used.

\section{Model Development}

TFM was first used in gas and particle flow systems in the 1960s [11,12], and the complete model was proposed by Drew in 1983 [13]. In TFM, the granular flows are modeled as continuous fluid flows. The random motions of particles resulting from the interactive collisions of particles has a dominant effect on the flow behavior [3]. The granular interactions are commonly modeled based on the kinetic theory of granular flow (KTGF) [14]. TFM coupled with KTGF has been used for modeling dense granular flow in rotating drums since 2007 [15]. KTGF is a well-defined model but is limited to dilute systems due to the assumption of instantaneous binary collisions [16]. However, when the concentration of particles in rotating drums is high, instead of instantaneous collisions, the contact between the particles is long-lasting and the particles slide over each other [17]. In this situation, frictional solids stress models should be added. In addition, the wall shear stress plays an important role in the granular flow in rotating drums, especially for those without flights (also called liner or lifter in literature). Therefore, the boundary condition of the wall is very important in the simulation, which is also summarized in this paper.

\subsection{TFM Coupled with KTGF}

The partial differential equations of two-phase flow in TFM are established by using the single-phase hydrodynamic equations combined with the concept of volume fraction. Therefore, the conservation equations of each phase's mass, momentum, and energy are solved separately in the unified Eulerian coordinate system. Each phase has its volume, velocity, and pressure [18]. Because of the random motions of particles in a granular flow, which are similar to the motions of molecules of gas, the concepts in the kinetic theory are borrowed to model and analyze granular flow behavior [19]. In KTGF, particles are analogous to gas molecules. Similar to the molecular temperature of molecular thermal motion, the concept of "granular temperature" is used to reflect the degree of particle velocity fluctuation, and the expressions of particle pressure and viscosity are derived using the Boltzmann differential equation of particle velocity distribution function [20]. The relevant equations of TFM coupled with KTGF are listed in Table 1 [10]. When there are two particle phases, TFM changes from the original gas-solid two-phase model to the gas-solid-solid three-phase model. At this time, by adding different solid forces based on the original uniform particle flow, the model will be suitable for predicting binary particle mixing. In addition to adding one phase to the governing equation, other relevant equations have been changed, as shown in Table 2 [21]. 
Table 1. Governing equations and constitutive equations.

The continuity equations for the gas phase and solid phase

$$
\begin{gathered}
\frac{\partial}{\partial t}\left(\alpha_{g} \rho_{g}\right)+\nabla \cdot\left(\alpha_{g} \rho_{g} \vec{v}_{g}\right)=0 \\
\frac{\partial}{\partial t}\left(\alpha_{s} \rho_{s}\right)+\nabla \cdot\left(\alpha_{s} \rho_{s} \vec{v}_{s}\right)=0 \\
\alpha_{s}+\alpha_{g}=1
\end{gathered}
$$

The conservation equations of momentum for the gas phase and solid phase

$$
\begin{gathered}
\frac{\partial}{\partial t}\left(\alpha_{g} \rho_{g} \vec{v}_{g}\right)+\nabla \cdot\left(\alpha_{g} \rho_{g} \vec{v}_{g} \vec{v}_{g}\right)=-\alpha_{g} \nabla p+\nabla \cdot \overline{\bar{\tau}}_{g}+\alpha_{g} \rho_{g} \vec{g}+K_{s g}\left(\vec{v}_{s}-\vec{v}_{g}\right) \\
\frac{\partial}{\partial t}\left(\alpha_{s} \rho_{s} \vec{v}_{s}\right)+\nabla \cdot\left(\alpha_{s} \rho_{s} \vec{v}_{s} \vec{v}_{s}\right)=-\alpha_{s} \nabla p-\nabla p_{s}+\nabla \cdot \overline{\bar{\tau}}_{s}+\alpha_{s} \rho_{s} \vec{g}+K_{s g}\left(\vec{v}_{g}-\vec{v}_{s}\right)
\end{gathered}
$$

Solid pressure

$$
p_{s}=\alpha_{s} \rho_{s} \Theta_{s}+2 \alpha_{s}^{2} \rho_{s} g_{0} \Theta_{s}\left(1+e_{s}\right)
$$

Radial distribution function [22]

$$
g_{0}=\frac{1}{1-\left(\frac{\alpha_{s}}{\alpha_{s, \max }}\right)^{\frac{1}{3}}}
$$

Stress-strain tensor for gas phase and solid phase

$$
\begin{gathered}
\overline{\bar{\tau}}_{g}=\alpha_{g} \mu_{g}\left[\nabla \vec{v}_{g}+\nabla \vec{v}_{g}^{T}\right]-\frac{2}{3} \alpha_{g} \mu_{g} \nabla \cdot \vec{v}_{g} \overline{\bar{I}} \\
\overline{\bar{\tau}}_{s}=\alpha_{s} \mu_{s}\left[\nabla \vec{v}_{s}+\nabla \vec{v}_{s}^{T}\right]+\alpha_{s}\left(\lambda_{s}-\frac{2}{3} \mu_{s}\right) \nabla \cdot \vec{v}_{s} \overline{\bar{I}}
\end{gathered}
$$

Shear viscosity of solid phase [23]

$$
\begin{gathered}
\mu_{s}=\mu_{s, \text { col }}+\mu_{s, k i n} \\
\mu_{s, c o l}=\frac{4}{5} \alpha_{s} \rho_{s} d_{s} g_{0}\left(1+e_{s}\right)\left(\frac{\Theta_{s}}{\pi}\right)^{\frac{1}{2}} \\
\mu_{s, k i n}=\frac{10 \rho_{s} d_{s} \sqrt{\Theta_{s} \pi}}{96 g_{0}\left(1+e_{s}\right)}\left[1+\frac{4}{5} \alpha_{s} g_{0}\left(1+e_{s}\right)\right]^{2}
\end{gathered}
$$

Bulk viscosity of solid phase [24]

$$
\lambda_{s}=\frac{4}{3} \alpha_{s}^{2} \rho_{s} d_{s} g_{0}\left(1+e_{s}\right)\left(\frac{\Theta_{s}}{\pi}\right)^{\frac{1}{2}}
$$

The transport equation of the granular temperature [25]

$$
\begin{gathered}
\frac{3}{2}\left[\frac{\partial}{\partial t}\left(\alpha_{s} \rho_{s} \Theta_{s}\right)+\nabla \cdot\left(\alpha_{s} \rho_{s} \vec{v}_{s} \Theta_{s}\right)\right]=\left(-p_{s} \bar{I}+\overline{\bar{\tau}}_{s}\right): \nabla \vec{v}_{s}+\nabla \cdot\left(k_{\Theta_{s}} \nabla \Theta_{s}\right)-\gamma_{\Theta_{s}}+\varphi_{g s} \\
k_{\Theta_{s}}=\frac{150 \rho_{s} d_{s} \sqrt{\Theta_{s} \pi}}{384 g_{0}\left(1+e_{s}\right)}\left[1+\frac{64}{5} \alpha_{s} g_{0}\left(1+e_{s}\right)\right]^{2}+2 \alpha_{s}^{2} \rho_{s} d_{s} g_{0}\left(1+e_{s}\right)\left(\frac{\Theta_{s}}{\pi}\right)^{\frac{1}{2}} \\
\gamma_{\Theta_{s}}=3\left(1-e_{s}{ }^{2}\right) \alpha_{s}{ }^{2} \rho_{s} g_{0} \Theta_{s}\left(\frac{4}{d_{s}} \sqrt{\frac{\Theta_{s}}{\pi}}-\nabla \cdot \overrightarrow{v_{s}}\right) \\
\varphi_{g s}=-3 K_{s g} \Theta_{s}
\end{gathered}
$$

The interphase momentum exchange coefficient of gas and solid [23]

$$
\begin{aligned}
& K_{s g}=K_{g s}= \begin{cases}\frac{150 \mu_{g}\left(1-\alpha_{g}\right) \alpha_{s}}{\alpha_{g} d_{s}^{2}}+\frac{1.75 \alpha_{s} \rho_{g}\left|\vec{v}_{g}-\vec{v}_{s}\right|}{d_{s}} & \alpha_{g} \leq 0.8 \\
\frac{3 C_{D} \rho_{g} \alpha_{s} \vec{v}_{g}-\vec{v}_{s} \mid}{4 d_{s}} \alpha_{g}^{-1.65} & \alpha_{g}>0.8\end{cases} \\
& C_{D}=\left\{\begin{array}{cc}
\frac{24}{\operatorname{Re}}\left[1+0.15 R e^{0.687}\right] & \operatorname{Re}<1000 \\
0.44 & \operatorname{Re} \geq 1000
\end{array}\right. \\
& \operatorname{Re}=\frac{\alpha_{g} \rho_{g} d_{s}\left|\vec{v}_{g}-\vec{v}_{s}\right|}{\mu_{g}}
\end{aligned}
$$


Table 2. Equations for gas-solid-solid three-phase model.

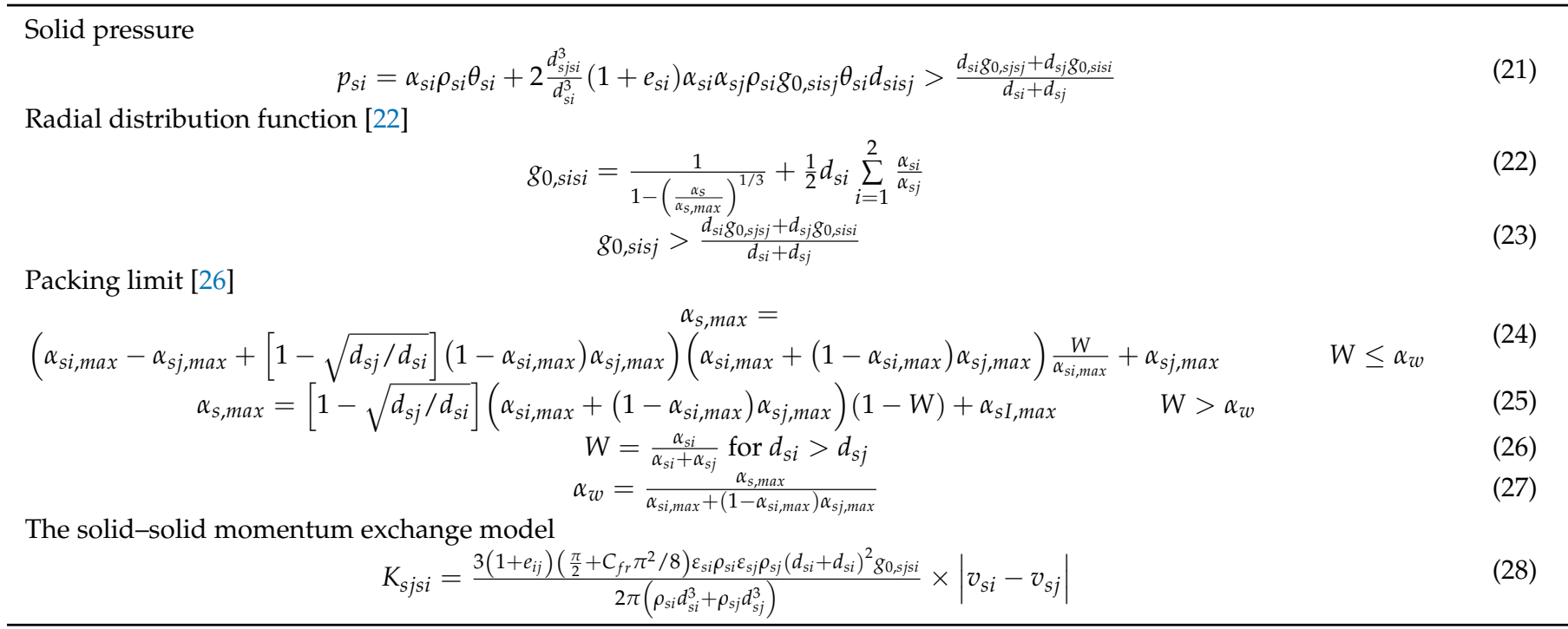

Although the TFM coupled with KTGF is theoretically suitable for dilute particle flow, several researchers $[27,28]$ used the model to simulate the dense particle flow in the rotating drum and considered that the model is applicable for the calculation of dense particle flow. The errors between the simulation results and the experimental results were pointed out in their work, but the authors believe that the errors are acceptable.

\subsection{Frictional Solids Stress Model}

The contact between dense particles in the rotating drum is lasting friction rather than instantaneous collision, so the generation of stress is mainly due to friction between particles. Therefore, it is more reasonable to simulate the dense granular flow after adding the frictional solids stress model and frictional viscosity model. It is necessary to define a critical particle phase concentration, that is, to set the standard for distinguishing dilute or dense granular flow. The critical particle phase fraction given in the literature is 0.5 [10]. The commonly used frictional viscosity model is Schaeffer's model and Johnson and Jackson model.

Schaeffer's model [22]:

$$
\mu_{s, f r}=\frac{p_{s} \sin \beta}{2 \sqrt{I_{2 D}}}
$$

where $\beta$ is the angle of internal friction, and $I_{2 \mathrm{D}}$ is the second invariant of the deviator of the strain rate tensor.

Johnson and Jackson model [29]:

$$
\begin{gathered}
\mu_{s, f r}=p_{s, f r} \sin \beta \\
P_{s, f r}=F r \frac{\left(\alpha_{s}-\alpha_{s, \text { min }}\right)^{n}}{\left(\alpha_{s, \text { max }}-\alpha_{s}\right)^{p}}
\end{gathered}
$$

where the coefficients, $n=2$, and $p=5$. The critical value for the frictional stress added to the stress predicted by the kinetic theory is $\alpha_{\min }=0.5$.

However, the author found that the flow pattern and the averaged tangential velocity of particles along the radius at $30^{\circ}$ to the vertical in a rotating drum predicted by the above two models was quite different from the experimental results [10]. Thus, a new frictional viscosity model was proposed and used to analyze the particle flow process in the rotating drum [10]:

$$
\mu_{s, f r}=\varepsilon \cdot P_{s}
$$


where $\varepsilon$ is a coefficient with a unit of s.

Although most researchers believe that the reason why TFM coupled with KTGF is not suitable for dense particle flow calculation is the lack of frictional viscosity, other researchers hold different views. Huang et al. [30-32] believed that the reason lies in the kinetic viscosity. They proposed a dynamic angle of repose fitting and a bed surface fitting to modify the kinetic viscosity of granular flow, and confirmed its applicability of simulating the segregation phenomenon caused by different particle sizes in the rotating drum. Although researchers have proposed several improved models and obtained good research results, these models have a limited scope of use and there is still a lack of a general model. On the other hand, Jop et al. [33,34] proposed a visco-plastic constitutive law to describe dense granular flows from a rheological point of view. They succeeded to fit the surface velocity profile for a steady unidirectional flow down an inclined plane with walls. Then, Cortet et al. [35] confronted this visco-plastic description of granular flows with steady surface flows observed in a rotating drum; however, they found that it was unapplicable for the multi-directional flow in the rotating drum. Another constitutive model for well-developed, dense granular flow was proposed by Henann et al. [36]. The major assumption of the model is that steady flow progresses at constant volume, so it is also not suitable for dense granular flow in a rotating drum. Similarly, Guo et al. [37] proposed a constitutive relationship for solids stress that predicts fluid-solid transitions. They added the solids pressure of the Schaeffer's model at maximum packing, to prevent the overpacking of particles, and combine it with the equations of Srivastava and Sundaresan [38] to model frictional solids pressure and solids viscosity. Moreover, DEM has been applied to this area since the 1990s, which is much longer than TFM [39,40]. Recently, Witt et al. [41] proposed a generic hierarchical approach in which DEM modeling is used to determine constitutive relationships which are then used in CFD modeling. The hierarchical technique exploits the individual strengths of both DEM and CFD methods in a sequential manner. These are valuable guides for developing general constitutive relationships for TFM.

\subsection{Boundary Condition Model}

The setting of boundary conditions will directly affect the prediction results of the particle flow behavior, either for uniform particle flow or binary particle mixing. Therefore, it is necessary to understand the mechanism of boundary conditions of different phases and set them reasonably in the calculation. For gas, the common wall boundary condition is no slip. For solids, it is necessary to select non-slip, partial slip, or free slip according to the actual situations $[42,43]$. The non-slip boundary condition assumes that the velocity of the particles at the wall in the normal and tangential directions is zero, and the free slip boundary condition assumes that the resistance of the particles by the wall is zero [27]. To quantify the partial slip boundary conditions, Johnson and Jackson proposed the calculation formula of wall boundary conditions [29]:

$$
\vec{\tau}_{s}=-\frac{\pi}{6} \sqrt{3} \varphi \frac{\alpha_{s}}{\alpha_{s, \max }} \rho_{s} g_{0} \sqrt{\Theta_{s}} \vec{v}_{s w}-N_{f} \tan \delta \frac{\vec{v}_{s w}}{\left|\vec{v}_{s w}\right|}
$$

where $\varphi$ is specularity coefficient, defined as the average fraction of the relative tangential momentum transferred by the collision between the particle and the wall [31]. $\vec{v}_{s w}$ is the relative velocity of the particle in contact with the wall, $N f$ is a normal frictional component of stress, and $\zeta$ is the internal angle of friction between the particles and the wall. The first and second terms on the right side of this equation represent the wall shear stress due to collision and friction between the particles and the wall.

Although the granular flow is very sensitive to the choice of boundary condition, only the collision shear stress of the boundary condition is considered while the friction shear stress is ignored in most studies [27,30]. The possible reasons are, on the one hand, the specularity coefficient is easy to set in the boundary condition using the commercial software Fluent, while user-defined functions are necessary when considering the two parts 
of shear stress. On the other hand, direct experimental measurement is not feasible for the specularity coefficient, while the model verification can be completed by continuously adjusting the specularity coefficient through the trial-and-error method. The authors in the present paper believe that considering the friction shear stress is more consistent with the actual situation, so we discuss the complete boundary condition model, and demonstrate that the specularity coefficient and angle of friction are fixed constants of the same granular flow in a rotating drum with different rotational speeds [10].

\section{Model Application}

The behavior of particle flow is affected by many variables related to system geometry, operational condition, and material properties [7]. Rotational speed, which is an important operating parameter of the rotating drum, has attracted the attention of researchers for a long time. Ingram et al. [44] summarized the flow of dense particles in the rotating drum without flights at different rotational speeds into six patterns: sliding, collapsing, rolling, cascading, cascading, and centrifuging. In addition, the particles in the rotating drum are usually different in size, density and shape in practical application. However, only uniform particles with the same properties and binary particles with different sizes in rotating drums were found in the literature, as seen in Table 3. Thus, the research status of these two types will be introduced below. In addition, the unique feature of using the model for simulating rotating drums is the performance of rotation. It is depicted that both the moving mesh and moving wall were used in Table 3.

\subsection{The Validation of the Model}

An important step before using a model is validation. Usually, the model is validated by comparison with experiment results. Therefore, before the analysis of model application, how the model is validated is worthy of attention. A column named validation basis is given in Table 3. It is easy to see that for the drum with flights, solids holdup in the flight is often used as a comparison object. While for the drum without flight, the velocity distribution of particles is used the most, especially for drums with uniform particles. End-view bed profiles are used for rotating drums with binary particles inside because there is often a core structure of segregation, or other clear structures can be found, and it is easy to make qualitative comparison. It should be noted that the comparison using granular temperature is not found, although it is the most direct way for the validation of the model. 
Table 3. Summary of the simulation condition.

\begin{tabular}{|c|c|c|c|c|c|c|c|c|c|c|}
\hline $\begin{array}{c}\text { Year of } \\
\text { Publication }\end{array}$ & Focus of the Study & Validation Basis & $\begin{array}{l}\text { Rotation } \\
\text { Method }\end{array}$ & $\underset{(\mathrm{mm})}{\mathrm{D}}$ & $\begin{array}{c}\mathrm{L} \\
(\mathrm{mm})\end{array}$ & $\begin{array}{l}\text { Flight } \\
\text { or Not }\end{array}$ & $\begin{array}{c}\text { Particle } \\
\text { Type }\end{array}$ & $\underset{(\mathrm{mm})}{\mathrm{d}}$ & $\begin{array}{c}\rho_{\mathrm{s}} \\
\left(\mathrm{kg} / \mathrm{m}^{3}\right)\end{array}$ & $\begin{array}{c}\text { Particle } \\
\text { Shape }\end{array}$ \\
\hline 2012 [45] & $\begin{array}{l}\text { Dynamic characteristics and the } \\
\text { rheology of a granular viscous } \\
\text { flow scale up }\end{array}$ & $\begin{array}{c}\text { Particle velocity and } \\
\text { dimensionless active layer } \\
\text { thickness }\end{array}$ & - & 400 & - & No & Uniform & 1.5 & 2900 & Spherical \\
\hline 2013 [46] & Particle dynamic behavior & $\begin{array}{l}\text { Solid flow regime and velocity } \\
\text { distribution }\end{array}$ & - & 195 & 500 & No & Uniform & $1.09 / 3.68$ & 2460 & Spherical \\
\hline 2015 [17] & $\begin{array}{l}\text { The effect of operating } \\
\text { conditions on solids flow }\end{array}$ & Solids hold up in the flight & moving mesh & 108 & 500 & Yes & Uniform & $\begin{array}{c}1.09 / 1.84 / 2.56 \\
2.56\end{array}$ & $\begin{array}{l}2455 \\
2090\end{array}$ & Spherical \\
\hline 2016 [47] & $\begin{array}{l}\text { Heat transfer and mixing } \\
\text { characteristics }\end{array}$ & $\begin{array}{l}\text { Velocity and temperature of } \\
\text { particles }\end{array}$ & - & 203 & - & No & Uniform & 2.5 & 2627 & Spherical \\
\hline 2017 [27] & $\begin{array}{l}\text { Boundary condition effects on } \\
\text { the particle dynamic flow }\end{array}$ & $\begin{array}{l}\text { Solids hold up in the flight, the } \\
\text { bed height and solid volume } \\
\text { fraction distribution }\end{array}$ & moving mesh & 108 & 500 & Yes & Uniform & 1.09 & 2455 & Spherical \\
\hline 2017 [48] & $\begin{array}{l}\text { The effects of specularity and } \\
\text { restitution coefficients under } \\
\text { different solid-flow regimes }\end{array}$ & $\begin{array}{l}\text { Solid volume fraction } \\
\text { distribution }\end{array}$ & moving mesh & 300 & 450 & Yes & Uniform & 25 & 7890 & Spherical \\
\hline 2017 [49] & $\begin{array}{l}\text { The effects of parameters on heat } \\
\text { transfer characteristics }\end{array}$ & $\begin{array}{c}\text { Average temperature of granular } \\
\text { materials }\end{array}$ & moving wall & 300 & 350 & Yes & Uniform & 1 & 3900 & Spherical \\
\hline 2018 [50] & $\begin{array}{l}\text { The effects of parameters on the } \\
\text { hydrodynamic and granular } \\
\text { temperature of particles }\end{array}$ & Particle velocity & moving wall & 215 & - & No & Uniform & 6.2 & 1164 & Spherical \\
\hline 2018 [51] & $\begin{array}{c}\text { Irregular particle (non-spherical) } \\
\text { dynamics }\end{array}$ & $\begin{array}{l}\text { Rice grains velocities and drum } \\
\text { transverse plane }\end{array}$ & $\begin{array}{l}\text { moving wall } \\
\text { and moving } \\
\text { mesh }\end{array}$ & 390 & $20 / 30 / 40$ & No & Uniform & $3.44 *$ & 1465 & $\begin{array}{c}\text { Non- } \\
\text { spherical }\end{array}$ \\
\hline 2019 [28] & $\begin{array}{l}\text { The effects of parameters on the } \\
\text { charge of solid in the flight }\end{array}$ & $\begin{array}{l}\text { Solids hold up in the flight and } \\
\text { solid volume fraction } \\
\text { distribution }\end{array}$ & moving mesh & 108 & 500 & Yes & Uniform & $\begin{array}{l}1.09 \\
1.02\end{array}$ & $\begin{array}{c}1551 \\
963\end{array}$ & Spherical \\
\hline $2020[10]$ & $\begin{array}{l}\text { Solid frictional viscosity and wall } \\
\text { friction }\end{array}$ & Particle velocity and flow pattern & moving mesh & 100 & - & No & Uniform & 3 & 2500 & Spherical \\
\hline
\end{tabular}


Table 3. Cont.

\begin{tabular}{|c|c|c|c|c|c|c|c|c|c|c|}
\hline $\begin{array}{l}\text { Year of } \\
\text { Publication }\end{array}$ & Focus of the Study & Validation Basis & $\begin{array}{l}\text { Rotation } \\
\text { Method }\end{array}$ & $\underset{(\mathrm{mm})}{\mathrm{D}}$ & $\underset{(\mathrm{mm})}{\mathrm{L}}$ & $\begin{array}{l}\text { Flight } \\
\text { or Not }\end{array}$ & $\begin{array}{l}\text { Particle } \\
\text { Type }\end{array}$ & $\underset{(\mathrm{mm})}{\mathrm{d}}$ & $\begin{array}{c}\rho_{\mathrm{s}} \\
\left(\mathrm{kg} / \mathrm{m}^{3}\right)\end{array}$ & $\begin{array}{l}\text { Particle } \\
\text { Shape }\end{array}$ \\
\hline $2021[52]$ & $\begin{array}{l}\text { The comparison between the } \\
\text { Eulerian (CFD) and the } \\
\text { Lagrangian (DEM) approaches }\end{array}$ & $\begin{array}{l}\text { Solids hold up in the flight and } \\
\text { solid volume fraction } \\
\text { distribution }\end{array}$ & moving mesh & 108 & 500 & Yes & Uniform & 1.09 & 2455 & Spherical \\
\hline 2007 [15] & $\begin{array}{l}\text { Main features of solids motion } \\
\text { and segregation }\end{array}$ & $\begin{array}{l}\text { Particle velocity and } \\
\text { concentration }\end{array}$ & - & 240 & 1000 & No & Binary & $1.5 / 3$ & 2600 & Spherical \\
\hline 2013 [32] & $\begin{array}{l}\text { Particle segregation and model } \\
\text { of granular viscosity }\end{array}$ & End-view bed profile & - & 45 & 50 & No & Binary & $0.385 / 0.775$ & 2500 & Spherical \\
\hline $2017[30]$ & $\begin{array}{l}\text { Particle segregation and model } \\
\text { of granular viscosity }\end{array}$ & End-view bed profile & - & 500 & 500 & No & Binary & $0.385 / 0.545 / 0.775$ & 2500 & Spherical \\
\hline 2017 [31] & $\begin{array}{l}\text { Effects of specularity coefficient } \\
\text { on particle segregation }\end{array}$ & End-view bed profile & - & 500 & 500 & No & Binary & $0.385 / 0.545 / 0.775$ & 2500 & Spherical \\
\hline 2020 [21] & $\begin{array}{c}\text { Mixing and segregation of } \\
\text { particles }\end{array}$ & $\begin{array}{l}\text { The evolution of the degree of } \\
\text { mixing and mixing process }\end{array}$ & - & 150 & 10 & No & Binary & $3 / 1.5$ & 2600 & Spherical \\
\hline
\end{tabular}

* Volume diameter. 


\subsection{Study on the Flow of Dense Uniform Particles}

In order to simplify the simulation, uniform particles are assumed in most studies, even though they are rarely found in practice. Under this assumption, the model is verified by comparing it with laboratory-scale experiments in which uniform particles are used [10,50].

For the dense uniform particle flow in the rotating drum without flights, Demagh et al. [45] studied the particle flow characteristics in the two flow states of rolling and cascading, and found that the particle velocity direction on the particle bed surface is not always parallel to the bed surface, and there are included angles in some positions, indicating that the particles will not slide or roll, but jump when moving. Santos et al. [46] identified different regimes (rolling, cascading, cataracting and centrifuging) of solids in motion in a rotating drum. Furthermore, Delele et al. [42] used the model to study the effects of rotational speed, filling level, feed speed, and drum inclination angle on particle flow, and found that the particle flow near the surface of the particle bed has a strong entrainment effect on the transverse air flow. Similarly, the effects of rotational speed, restitution coefficient and particle size on the hydrodynamics of the particle was investigated by Taghizadeh et al. [50]. It is worth mentioning that the effects of these parameters on the granular temperature of particles was also studied. They found that the particle-particle restitution coefficient and rotational speed play a significant role in the granular temperature, and consequently on the hydrodynamic behavior of the bed. Moreover, the TFM-coupled KTGF and diverse heat transfer models were used to predict heat transfer in a rotating drum, and it was revealed that the bed surface velocity characteristic peak is located at the center and down the edges [47]. In addition, the authors of the present paper made a discussion of the boundary conditions of the rotating drum using the Johnson and Jackson model [10].

For the dense uniform particle flow in the rotating drum with flights, the configuration of flights plays an important role on the granular flow. The effects of the number of flights [28], flight folding angle [28] and flight shape [27,49,52] on particle flow behavior were analyzed. The solid-hold-up in the flight was well predicted. Similar to the rotating drum without flights, the particle flow pattern, the effects of the operational parameters, the effects of the model parameters, and the heat transfer were also analyzed [17,48,49].

Moreover, Nascimento et al. [52] proposed for the first time that considering the turbulence effect in the model can better predict the active region and passive region of the particle bed. Figure 1 gives representative results.

The above studies are aimed at spherical particles, while the flow process of uniform non-spherical particles in a rotating drum was studied by Benedito et al. [51]. It was found that by giving appropriate parameters, the model could be verified by comparing the rice grain velocities and the drum transverse plane with the experimental results. It is worth noting that this verification is accidental, because the parameters are given by the trial-and-error method instead of experimental measurement. In essence, the numerical model for non-spherical particles has not been developed.

\subsection{Study on Mixing and Segregation of Dense Binary Particles}

Compared with uniform particles in rotating drums, the mixing and segregation of binary particles occur due to different particle properties, which are more complex. There are generally two types of mixing in horizontal rotating drums: longitudinal and transverse. Similar to mixing, there are also two types of segregation: radial and axial segregation. He et al. [15] first used the TFM coupled with KTGF to simulate binary particle segregation with different sizes in a rotating drum, which confirmed the predict applicability of the model. A clear core-shell structure in the transverse plane of the drum, in terms of the concentration of small and large particles, was predicted and an initial attempt was made to simulate the axial particle segregation. Santos et al. [53] conducted simulations to predict the mixing and segregation of particles in a rotating drum due to the different particle diameters. The predicted particle segregation was in good agreement with the experimental results. The internal structure of the bed material inside the drum which consisted of a symmetrical wing-shaped extension of small particles towards the drum end plates was observed. However, Huang et al. $[32,54]$ observed that the TFM coupled with KTGF failed 
to predict the mixing and segregation of the particles in the rotating drum they investigated; then, they proposed the dynamic angle of repose fitting (DARF) and bed surface fitting (BSF) to modify the kinetic viscosity of the model. The results showed that the modified model was useful for analyzing the radial and axial segregation of particles in the rotating drum. Although these studies predict the typical mixing and segregation of particles using the model, the degree of particle mixing or segregation was not quantified. Referring to mixing indices in DEM simulation and experimental research, a mixing index based on sampling information from the computational grids was established in our previous work [21]. The index was used for the quantitative analysis of the segregation degree of binary particles with different sizes in a rotating drum without a baffle, and drums with baffles of different shapes. It was found that the enhancement effect of the baffle on particle mixing was not obvious, and the mixing speed was too fast compared with the experimental results. Therefore, the TFM coupled with KTGF is applicable for predicting the mixing and segregation of binary particles in rotating drums, but the accuracy needs further discussion. The representative results are shown in Figure 2.
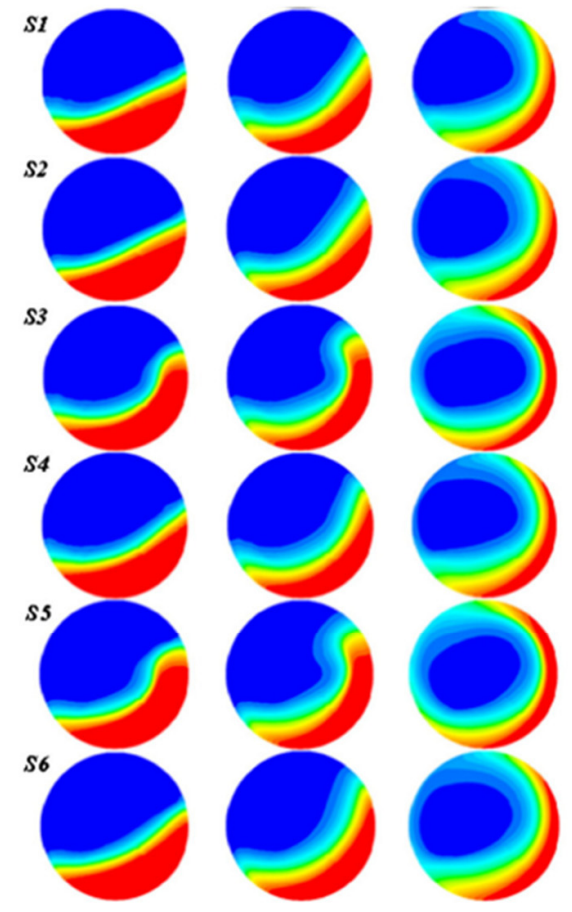

(a)

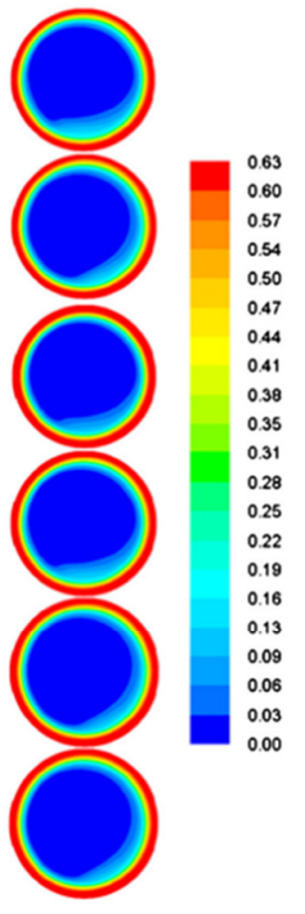

Figure 1. (a) Volume fraction of the granular solid phase of $3.68 \mathrm{~mm}$ and fill level of $31.40 \%$ for drum rotating at 1.45, 4.08, 8.91 and $16.4 \mathrm{rad} / \mathrm{s}$ from the left to the right [46]; (b) axial distribution of the tracer particle volume fraction after an injection time of $60 \mathrm{~s}$ for different operating conditions of the drum [42]; (c) solid volume fraction distributions (passive phase) without and with the $k$ - $\varepsilon$-turbulence model [52]. (Note: all the legends indicate volume fraction of particles).

Table 3 summarizes the relevant studies including the representative model applications described above. It can be seen that TFM coupled with KTGF has been used for modeling dense granular flow in rotating drums since 2007. It has been used for only 14 years. Zhu et al. [7] has given a detailed review of DEM used for granular flow in rotating drums; it can be easily noticed that DEM has a longer history and has been more popular in this area than TFM. However, they indicated that the number of particles that can be dealt with at the moment is limited. Moreover, although there are model advantages of TFM compared with DEM, such as low computing resources and suitability for industrial-scale modeling, the model is still used for a laboratory-scale rotating drum (diameter less than $0.5 \mathrm{~m}$ ), and no simulation for an industrial-scale rotating drum was found. 


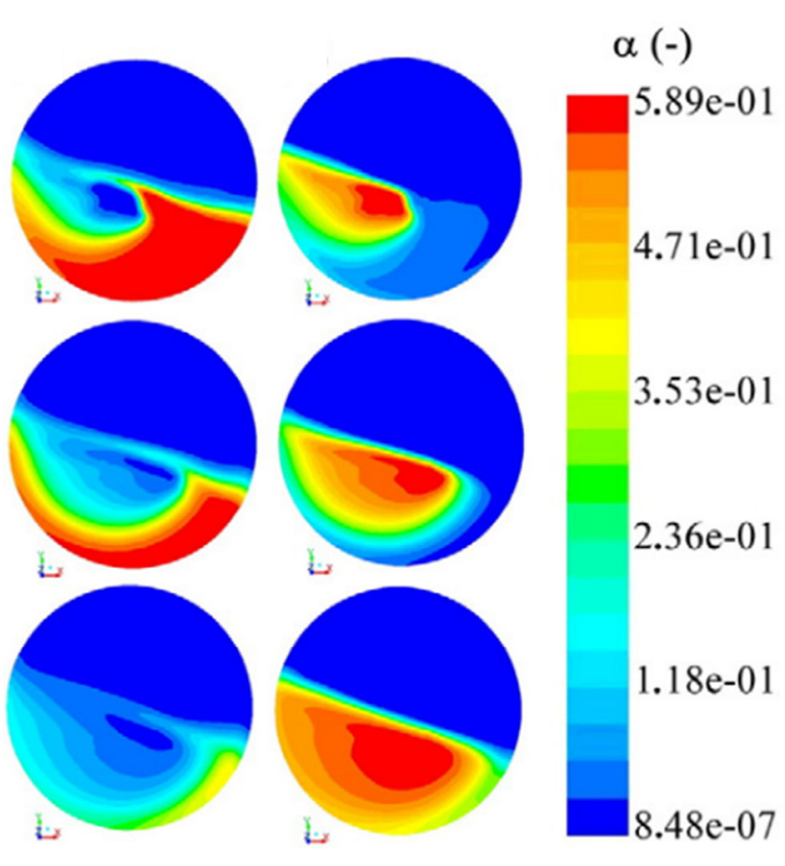

(a)

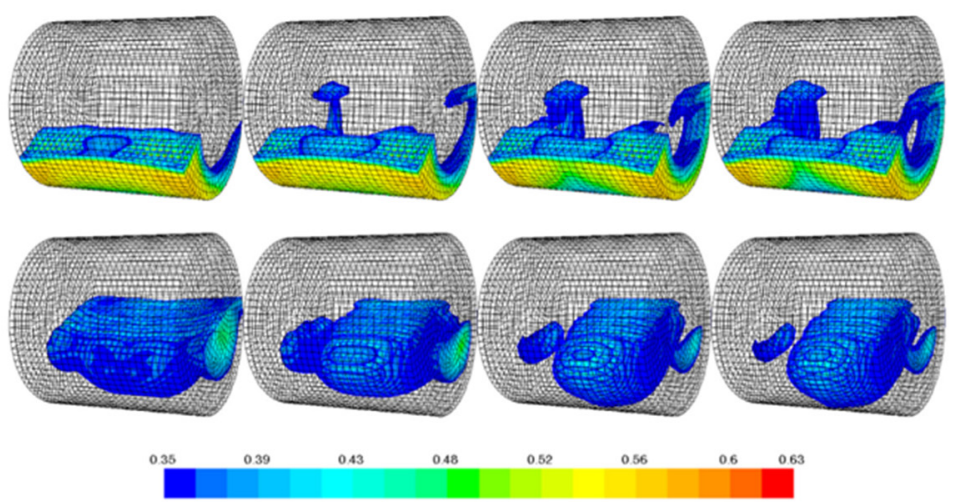

(b)

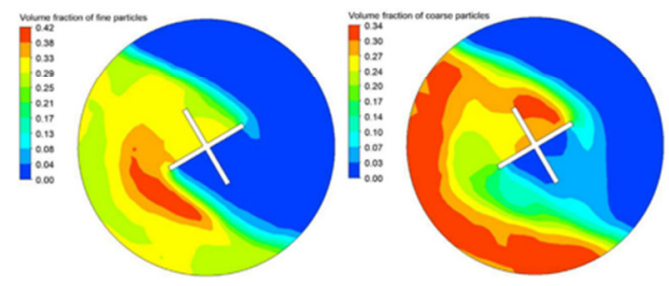

(c)

Figure 2. (a) Simulated drum transverse plane for the radial segregation analysis [53]; (b) the surface of the $0.775 \mathrm{~mm}$ solid phase (top row) and $0.385 \mathrm{~mm}$ solid phase (bottom row) [23]; (c) the mixing process of binary particles in the drum with " + " baffle [21]. (Note: all the legends indicate volume fraction of particles).

\section{Concluding Remarks}

In this paper, the research progress of the TFM coupled with KTGF in predicting the flow and mixing of dense particles in rotating drums is discussed, from the perspective of model development and model application. The following conclusions are obtained:

(1) TFM coupled with KTGF is generally used to study the dilute granular flow. In order to apply it to the dense granular flow in rotating drums, the frictional viscosity model is supplemented to consider the friction between particles due to long-term contact. Several frictional viscosity models are proposed for the dense particles flow and mixing in specific rotating drums, but a general model needs to be developed;

(2) The research on the flow and mixing of dense granular flow in the rotating drum began in 2007; thus, the development and application of the model are still in the exploratory stage. By properly adjusting the model parameters, the model can be used to study the uniform particle flow and binary particle mixing in the rotating drum with and without flights and achieve valuable results;

(3) The application of the model is flexible. The rotation of the drum can be performed by moving the wall or moving mesh. The validation of the model is easily completed by comparison with the experimental results of particle velocity distribution, particle volume fraction and solids hold up in the flight et al.

(4) Although the advantages of TFM compared with DEM include low computing resources and a suitability for industrial-scale simulation, the application of the TFM model is mainly focused on a laboratory-scale rotating drum (diameter less than $0.5 \mathrm{~m}$ ), and has not been applied to the prediction or analysis of a industrial-scale rotating drum.

As an effective technique, TFM coupled with KTGF has been used and will continue to be used to study the complex granular flow behavior in rotating drums. However, there is a long way to go for a general constitutive relation used in industrial-scale modeling. 
Author Contributions: Conceptualization, methodology, writing—original draft preparation, W.R.; writing-review and editing, Y.F.; supervision, B.L. All authors have read and agreed to the published version of the manuscript.

Funding: This research was funded by the State Key Laboratory of Process Automation in Mining \& Metallurgy (BGRIMM-KZSKL-2020-10).

Institutional Review Board Statement: Not applicable.

Informed Consent Statement: Not applicable.

Data Availability Statement: Not applicable.

Conflicts of Interest: The authors declare no conflict of interest.

\section{References}

1. Jaeger, H.M.; Nagel, S.R.; Behringer, R.P. The physics of granular materials. Phys. Today 1996, 49, 32-38. [CrossRef]

2. Dhakal, S. Experimental study of particle interactions in moderate to dense granular shear flows of disks. Condens. Matter 2017, 2, 2. [CrossRef]

3. Atydu, T. Experiments on a gravity-free dispersion of large solid spheres in a Newtonian fluid under shear. Proc. R. Soc. London. Ser. A Math. Phys. Sci. 1954, 225, 49-63. [CrossRef]

4. Yang, R.Y.; Zou, R.P.; Yu, A.B. Microdynamic analysis of particle flow in a horizontal rotating drum. Powder Technol. 2003, 130, 138-146. [CrossRef]

5. Ottino, J.M.; Khakhar, D.V. Mixing and segregation of granular materials. Annu. Rev. Fluid Mech. 2000, 32, 55-91. [CrossRef]

6. Dhakal, S. Shear flow characteristics of densely packed granular material subjected to slow deformations. J. Nepal Geol. Soc. 2013, 46. [CrossRef]

7. Zhu, H.P.; Zhou, Z.Y.; Yang, R.Y.; Yu, A.B. Discrete particle simulation of particulate systems: A review of major applications and findings. Chem. Eng. Sci. 2008, 63, 5728-5770. [CrossRef]

8. Zhu, H.P.; Zhou, Z.Y.; Yang, R.Y.; Yu, A.B. Discrete particle simulation of particulate systems: Theoretical developments. Chem. Eng. Sci. 2007, 62, 3378-3396. [CrossRef]

9. Zheng, Q.; Bai, L.; Yang, L.; Yu, A. 110th Anniversary: Continuum Modeling of Granular Mixing in a Rotating Drum. Ind. Eng. Chem. Res. 2019, 58, 19251-19262. [CrossRef]

10. Rong, W.; Feng, Y.; Schwarz, P.; Witt, P.; Li, B.; Song, T.; Zhou, J. Numerical study of the solid flow behavior in a rotating drum based on a multiphase CFD model accounting for solid frictional viscosity and wall friction. Powder Technol. 2020, 361, 87-98. [CrossRef]

11. Soo, S.L. Fluid Dynamics of Multiphase System; Blaisdell Press: New York, NY, USA, 1967.

12. Jackson, R. The mechanics of fluidized beds. I. The stability of the state of uniform fluidization. Trans. Inst. Chem. Engs. 1963, 41, 13-21.

13. Drew, D.A. Mathematical modeling of two-phase flow. Annu. Rev. Fluid Mech. 1983, 15, 261-291. [CrossRef]

14. Wang, J. Continuum theory for dense gas-solid flow: A state-of-the-art review. Chem. Eng. Sci. 2020, 215, 115428. [CrossRef]

15. He, Y.R.; Chen, H.S.; Ding, Y.L.; Lickiss, B. Solids motion and segregation of binary mixtures in a rotating drum mixer. Chem. Eng. Res. Des. 2007, 85, 963-973. [CrossRef]

16. Khalilitehrani, M.; Abrahamsson, P.J.; Rasmuson, A. Modeling dilute and dense granular flows in a high shear granulator. Powder Technol. 2014, 263, 45-49. [CrossRef]

17. Nascimento, S.M.; Santos, D.A.; Barrozo, M.A.S.; Duarte, C.R. Solids holdup in flighted rotating drums: An experimental and simulation study. Powder Technol. 2015, 280, 18-25. [CrossRef]

18. Zeneli, M.; Nikolopoulos, A.; Nikolopoulos, N.; Grammelis, P.; Karellas, S.; Kakaras, E. Simulation of the reacting flow within a pilot scale calciner by means of a three phase TFM model. Fuel Process. Technol. 2017, 162, 105-125. [CrossRef]

19. Mahmood, Z.; Dhakal, S.; Iwashita, K. Measurement of Particle Dynamics in Rapid Granular Shear Flows. J. Eng. Mech. 2009, 135, 285-294. [CrossRef]

20. Yu, L.; Ma, J.; Frear, C.; Zhao, Q.; Dillon, R.; Li, X.; Chen, S. Multiphase modeling of settling and suspension in anaerobic digester. Appl. Energy 2013, 111, 28-39. [CrossRef]

21. Rong, W.; Li, B.; Feng, Y.; Schwarz, P.; Witt, P.; Qi, F. Numerical analysis of size-induced particle segregation in rotating drums based on Eulerian continuum approach. Powder Technol. 2020, 376, 80-92. [CrossRef]

22. Ogawa, S.; Umemura, A.; Oshima, N. On the equations of fully fluidized granular materials. J. Appl. Math. Phys. 1980, 31, 483-493. [CrossRef]

23. Gidaspow, D.; Bezburuah, R.; Ding, J. Hydrodynamics of circulating fluidized beds: Kinetic theory approach. In Proceedings of the 7th Fluidization Conference, Gold Coast, Australia, 3-8 May 1992; pp. 75-82.

24. Lun, C.K.K.; Savage, S.B.; Jeffrey, D.J.; Chepurniy, N. Kinetic theories for granular flow: Inelastic particles in couette flow and slightly inelastic particles in a general flowfield. J. Fluid Mech. 1984, 140, 223-256. [CrossRef]

25. Gidaspow, D.; Ding, J. A bubbling fluidization model using kinetic theory of granular flow. AIChE J. 1990, 36, 523-538. [CrossRef] 
26. Fedors, R.F.; Landel, R.F. An Empirical method of estimating the void fraction in mixtures of uniform particles of different size. Powder Technol. 1979, 23, 225-231. [CrossRef]

27. Machado, M.V.C.; Nascimento, S.M.; Duarte, C.R.; Barrozo, M.A.S. Boundary conditions effects on the particle dynamic flow in a rotary drum with a single flight. Powder Technol. 2017, 311, 341-349. [CrossRef]

28. Nascimento, S.M.; Lima, R.M.; Brandão, R.J.; Duarte, C.R.; Barrozo, M.A.S. Eulerian study of flights discharge in a rotating drum. Can. J. Chem. Eng. 2019, 97, 477-484. [CrossRef]

29. Johnson, P.C.; Nott, P.; Jackson, R. Frictional-Collisional equations of motion for particulate flows with application to chutes. J. Fluid Mech. 1990, 210, 501-535. [CrossRef]

30. Huang, A.N.; Kuo, H.P. CFD simulation of particle segregation in a rotating drum. Part I: Eulerian solid phase kinetic viscosity. Adv. Powder Technol. 2017, 28, 2094-2101. [CrossRef]

31. Huang, A.N.; Kuo, H.P. CFD simulation of particle segregation in a rotating drum. Part II: Effects of specularity coefficient. Adv. Powder Technol. 2018, 29, 3368-3374. [CrossRef]

32. Huang, A.N.; Kao, W.C.; Kuo, H.P. Numerical studies of particle segregation in a rotating drum based on Eulerian continuum approach. Adv. Powder Technol. 2013, 24, 364-372. [CrossRef]

33. Jop, P.; Forterre, Y.; Pouliquen, O. A constitutive law for dense granular flows. Nature 2006, 441, 727-730. [CrossRef] [PubMed]

34. Jop, P. Rheological properties of dense granular flows. Comptes Rendus Phys. 2015, 16, 62-72. [CrossRef]

35. Cortet, P.P.; Bonamy, D.; Daviaud, F.; Dauchot, O.; Dubrulle, B.; Renouf, M. Relevance of visco-plastic theory in a multi-directional inhomogeneous granular flow. EPL 2009, 88, 14001. [CrossRef]

36. Henann, D.L.; Kamrin, K. A predictive, size-dependent continuum model for dense granular flows. Proc. Natl. Acad. Sci. USA 2013, 110, 6730-6735. [CrossRef] [PubMed]

37. Guo, Q.; Zhang, Y.; Padash, A.; Xi, K.; Kovar, T.M.; Boyce, C.M. Dynamically structured bubbling in vibrated gas-fluidized granular materials. Proc. Natl. Acad. Sci. USA 2021, 118, e2108647118. [CrossRef] [PubMed]

38. Srivastava, A.; Sundaresan, S. Analysis of a frictional-kinetic model for gas-particle flow. Powder Technol. 2003, 129, 72-85. [CrossRef]

39. Buchholtz, V.; Pöschel, T.; Tillemans, H.J. Simulation of rotating drum experiments using non-circular particles. Phys. A Stat. Mech. Its Appl. 1995, 216, 199-212. [CrossRef]

40. Wightman, C.; Moakher, M.; Muzzio, F.J.; Walton, O. Simulation of flow and mixing of particles in a rotating and rocking cylinder. AIChE J. 1998, 44, 1266-1276. [CrossRef]

41. Witt, P.J.; Sinnott, M.D.; Cleary, P.W.; Schwarz, M.P. A hierarchical simulation methodology for rotary kilns including granular flow and heat transfer. Miner. Eng. 2018, 119, 244-262. [CrossRef]

42. Delele, M.A.; Weigler, F.; Franke, G.; Mellmann, J. Studying the solids and fluid flow behavior in rotary drums based on a multiphase CFD model. Powder Technol. 2016, 292, 260-271. [CrossRef]

43. Santos, D.A.; Dadalto, F.O.; Scatena, R.; Duarte, C.R.; Barrozo, M.A.S. A hydrodynamic analysis of a rotating drum operating in the rolling regime. Chem. Eng. Res. Des. 2015, 94, 204-212. [CrossRef]

44. Ingram, A.; Seville, J.P.K.; Parker, D.J.; Fan, X.; Forster, R.G. Axial and radial dispersion in rolling mode rotating drums. Powder Technol. 2005, 158, 76-91. [CrossRef]

45. Demagh, Y.; Ben Moussa, H.; Lachi, M.; Noui, S.; Bordja, L. Surface particle motions in rotating cylinders: Validation and similarity for an industrial scale kiln. Powder Technol. 2012, 224, 260-272. [CrossRef]

46. Santos, D.A.; Petri, I.J.; Duarte, C.R.; Barrozo, M.A.S. Experimental and CFD study of the hydrodynamic behavior in a rotating drum. Powder Technol. 2013, 250, 52-62. [CrossRef]

47. Liu, H.; Yin, H.; Zhang, M.; Xie, M.; Xi, X. Numerical simulation of particle motion and heat transfer in a rotary kiln. Powder Technol. 2016, 287, 239-247. [CrossRef]

48. Machado, M.V.C.; Santos, D.A.; Barrozo, M.A.S.; Duarte, C.R. Experimental and Numerical Study of Grinding Media Flow in a Ball Mill. Chem. Eng. Technol. 2017, 40, 1835-1843. [CrossRef]

49. Li, M.; Ling, X.; Peng, H.; Cao, Z.; Wang, Y. An investigation on heat transfer of granular materials in the novel flighted rotary drum. Can. J. Chem. Eng. 2017, 95, 386-397. [CrossRef]

50. Taghizadeh, A.; Hashemabadi, S.H.; Yazdani, E.; Akbari, S. Numerical analysis of restitution coefficient, rotational speed and particle size effects on the hydrodynamics of particles in a rotating drum. Granul. Matter 2018, 20, 56. [CrossRef]

51. Benedito, W.M.; Duarte, C.R.; Barrozo, M.A.S.; dos Santos, D.A. An investigation of CFD simulations capability in treating non-spherical particle dynamics in a rotary drum. Powder Technol. 2018, 332, 171-177. [CrossRef]

52. Nascimento, S.M.; Lima, R.M.; Brandão, R.J.; Santos, D.A.; Duarte, C.R.; Barrozo, M.A.S. Comparison between the Eulerian (CFD) and the Lagrangian (DEM) approaches in the simulation of a flighted rotary drum. Comput. Part. Mech. 2021, 1-13. [CrossRef]

53. Santos, D.A.; Duarte, C.R.; Barrozo, M.A.S. Segregation phenomenon in a rotary drum: Experimental study and CFD simulation. Powder Technol. 2016, 294, 1-10. [CrossRef]

54. Huang, A.N.; Liu, L.C.; Kuo, H.P. The role of end wall shearing in the drum segregation band formation. Powder Technol. 2013, 239, 98-104. [CrossRef] 